\title{
Autumn Meeting of EPS Council
}

\section{7-28 November 1973, CERN, Geneva, Switzerland}

The following Council delegates had been invited to attend the meeting:

J. Aguilar Peris, Madrid

A. Alberigi-Quaranta, Modena

J. Auth, Berlin (DDR)

A.B. Berezin, Leningrad

C.M. Braams, Jutphaas

W. Buckel, Karlsruhe

F. Cap, Innsbruck

H.B.G. Casimir, Eindhoven

C. Castagnoli, Turin

R. Castaing, Orsay

M.H. Checinska, Warsaw

P.F. Chester, Leatherhead

N. Cindro, Zagreb

C. de Vries, Amsterdam

$\mathrm{G}$. Diemer, Eindhoven
Y. Eisenberg, Kehovot

Sir Brian Flowers, London
J. Friedel, Paris
H. Friedrich, Berlin (DDR)
K.E. Ganzhorn, Stuttgart
B.J. Green, Garching near Munich
B.P. Gregory, Paris
F. Gremmelmaier, Erlangen
A. Guinier, Paris
P.G. Hansen, Geneva
G. Harbeke, Affoltern am Albis
O.S. Heavens, York
T. Henriksen, Oslo
H. Hristov, Sofia
G. Jacobs, Ghent
L. Jansen, Geneva
W. Klose, Saarbrucken

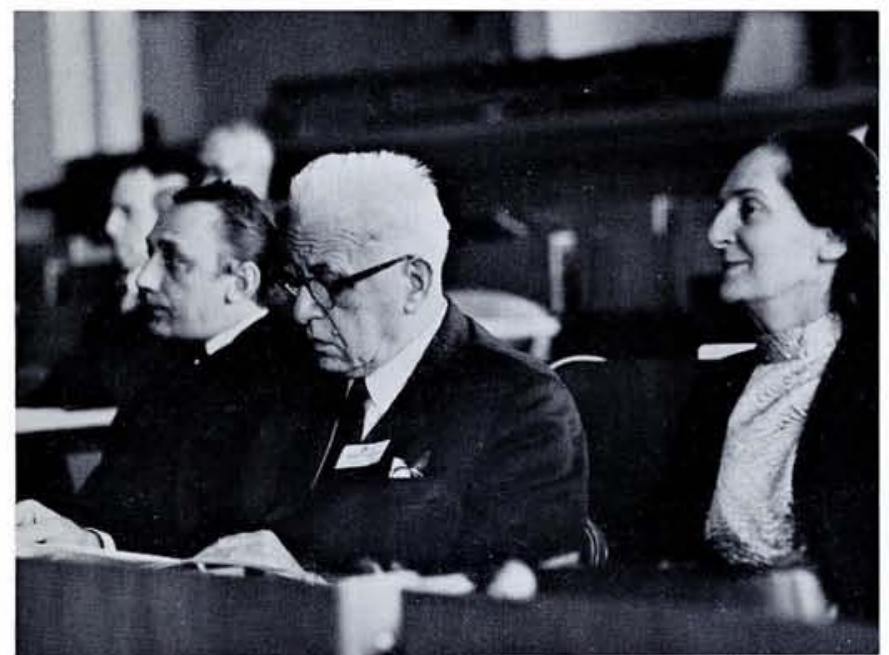

J. Kolodziejczak, M. Miesowicz and M.H. Checinska, delegates of the Polish Physical Society, attending the Council Meeting at Cern.

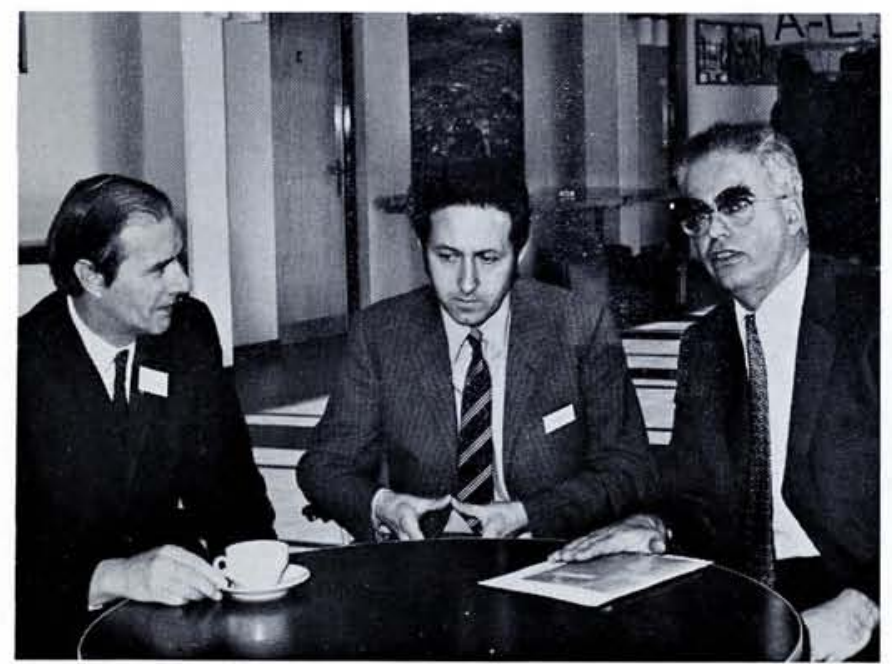

Chairmen of EPS Advisory Committees meet informally. Left to right - L.A.A. Thomas (Applied Physics and Physics in Industry), J. Depireux (Publications) and P. Radvanyi (Conferences).
J. Kolodziejczak, Warsaw N. Kurkcuoglu, Istanbul N. Kurti, Oxford D.M. Larkin, Galway A. Lösche, Leipzig S.O. Lundqvist, Gothenburg K.A. Mansikka, Turku Turku
Frankfurt am Main G. Marx, Budapest H. Mathieu-Faraggi, Bourg-la-Reine M. Matyas, Prague V. Meyer, Zurich M. Miesowicz, Cracow K.A. Muller, Ruschlikon N.R. Nilsson, Uppsala J.L. Olsen, Zurich
I. Otterlund, Lund . Pinto Peixoto, Lisbon A.M. Prokhorov, Moscow P. Radvanyi, Orsay R.A. Ricci, Padova T. Riste, Kjeller I. Siaus, Zagreb G.A. Smolensky, Leningrad G. Szigeti, Budapest P. Tanskanen, Oulu
L.A.A. Thomas, Wembley L.A.A. Thomas, Wembley
S. Titeica, Bucharest S. Titeica, Bucharest j.J. Went, Arnhem

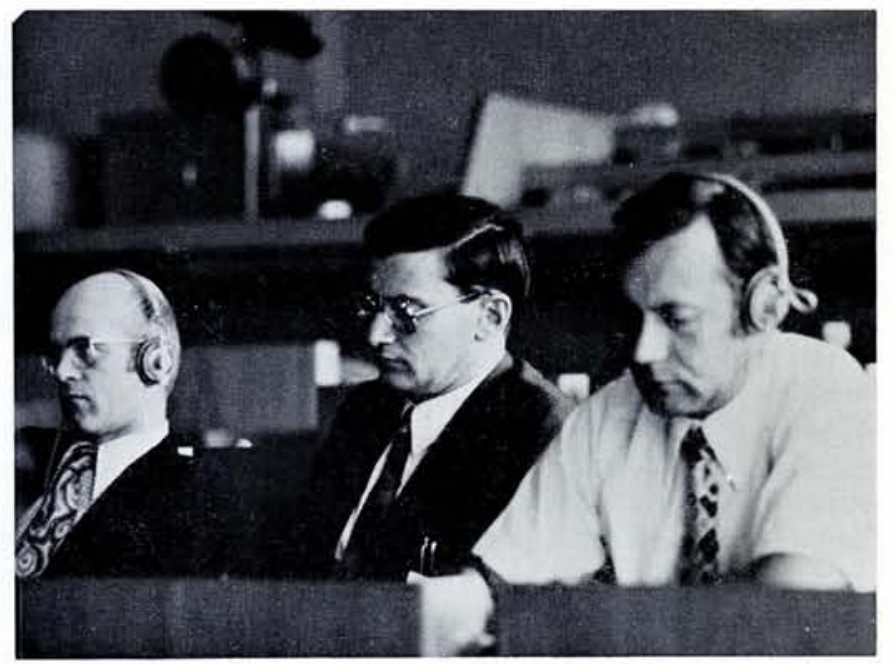

From left to right - D. Biskamp representing the Computational Physics Group, B.J. Green, delegate of Individual Ordinary Members and A.B. Berezin, delegate of the Department of General Physics and Astronomy of the USSR Academy of Sciences.

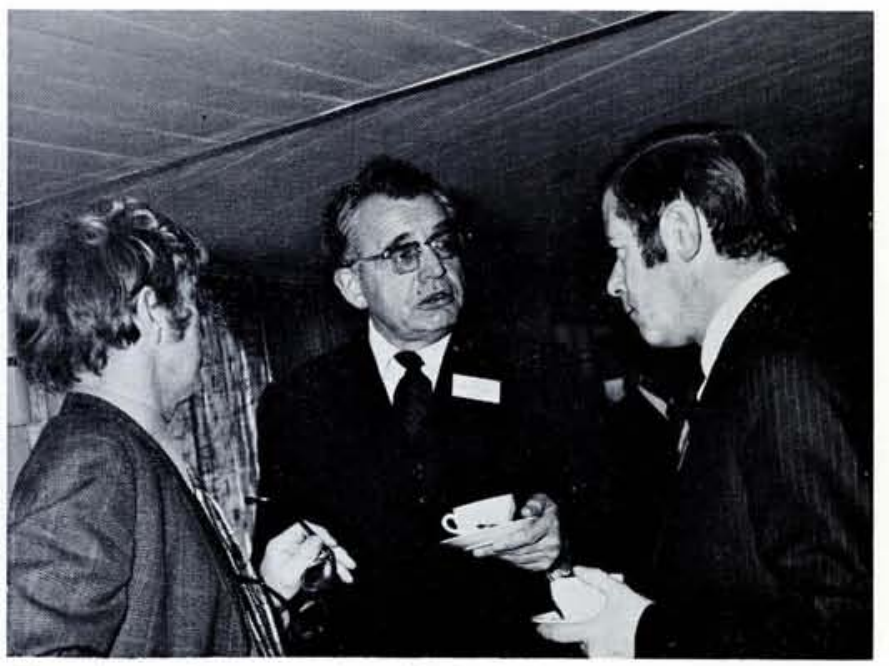

Discussion on finances at the coffee-break between O.S. Heavens, Treasurer, H.B.G. Casimir, President, and G. Thomas, Office Manager. 